\title{
Infraestrutura e desenvolvimento econômico: proposta de um modelo analítico *
}

\author{
Fernando Dall'Onder Sebben **
}

\begin{abstract}
Resumo
Este trabalho apresenta um modelo analítico para analisar o impacto das políticas públicas de infraestrutura no desenvolvimento econômico. Para tanto, utiliza duas varáveis principais: 1) padrão de relacionamento entre os setores público e privado, que representa o grau de cooperação entre os setores público e privado (autonomia inserida); 2) política infraestrutural, classificadas como horizontais, quando seu princípio norteador é a busca pela eficiência e têm como foco o fortalecimento de vantagens comparativas, e verticais, quando sua essência é a busca pela construção de capacidades produtivas e tecnológicas, articuladas à indústria, e seu foco é a criação de vantagens competitivas. Essa combinação dá origem a quatro tipos ideais, que correspondem a resultados esperados em políticas públicas: Estado Neo-utilitário, Estado Autônomo, Estado Facilitador e Estado Desenvolvimentista. O resultado apresenta um modelo analítico que permite classificar e avaliar satisfatoriamente as políticas públicas de infraestrutura e seu resultado esperado em termos de desenvolvimento econômico.
\end{abstract}

Palavras-chave: Desenvolvimento econômico; Política industrial; Política de infraestrutura.

\begin{abstract}
Infrastructure and economic development: proposal of an analytical model

This paper presents an analytical model to analyze the impact of public policy infrastructure on economic development. To do so, it uses two main variables: 1) the pattern of relationships between the public and private sectors, which is the degree of cooperation between the public and private sectors (embedded autonomy); 2) infrastructural policy, classified as horizontal when its guiding principle is the pursuit of efficiency and which are focused on the strengthening of comparative advantages, and vertical when its essence is building productive and technological capabilities, linked to the industry, and it is focused on the creation of competitive advantages. This combination gives rise to four ideal types, which correspond to expected results in public policy: Neo-utilitarian State, Autonomous State, Facilitating State and Developmental State. The result presents an analytical model that makes it possible to classify and satisfactorily evaluate infrastructure's public policy and its expected results in terms of economic development.
\end{abstract}

Keywords: Economic development; Industrial policy; Infrastructure policy.

JEL H54, O21, O25.

\section{Introdução}

Qual o impacto esperado dos projetos de infraestrutura sobre os processos de integração regional? De que modo eles se articulam com as estruturas produtivas nacionais? Qual seu impacto sobre o desenvolvimento econômico? Como a relação entre os setores público e privado condiciona a realização dos projetos? De que modo Estado e mercado

\footnotetext{
* Artigo recebido em 12 de julho de 2016 e aprovado em 24 de março de 2018.

** Analista Legislativo do Senado Federal, Brasília, DF, Brasil. E-mail: fdallonder@gmail.com.
} 
interagem? Essas perguntas dão suporte a um questionamento mais geral, que conforma o seguinte o problema de pesquisa: de que modo a política de infraestrutura interage e condiciona o processo de desenvolvimento?

Na tentativa de responder a essas questões, este trabalho utiliza uma combinação de variáveis que dá origem a uma tipologia, observada no gráfico a seguir:

Gráfico 1

Modelos de desenvolvimento a partir da relação entre políticas de infraestrutura e cooperação entre os setores público e privado

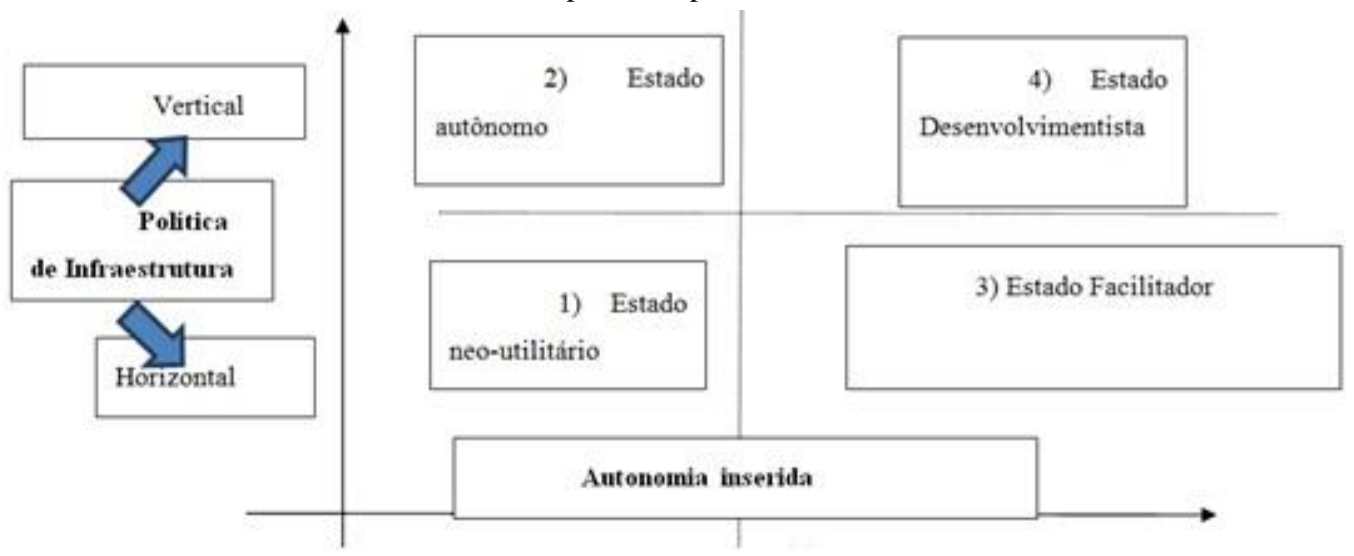

Fonte: Elaboração própria.

As variáveis independentes ${ }^{1}$ utilizadas são:

a) autonomia inserida, definida como o grau de cooperação entre os setores público e privado, a partir de uma operacionalização do conceito originalmente formulado por Peter Evans (Evans, 1993; 2004), classificado em baixo ou alto;

b) política de infraestrutura, definida como o conjunto de obras de transporte, energia e comunicações, classificada em horizontal ou vertical, a partir de uma adaptação do modelo analítico desenvolvido por Peres e Primi (2009) para avaliar as políticas industriais.

Conforme será detalhado na próxima seção, enquanto as políticas horizontais consistem, de um modo geral, em medidas genéricas voltadas para a qualificação de fatores de produção, sem distinguir setores específicos, as verticais estabelecem prioridades a partir de decisões estratégicas. Enquanto as primeiras tendem a reforçar vantagens comparativas existentes, as segundas visam criar vantagens competitivas.

(1) A organização da pesquisa em variáveis independente (causa) e dependente (resultado esperado) foi baseada em Van Evera (2002). 
A variável dependente é o modelo de desenvolvimento. Evidentemente, existem diversas abordagens para o conceito de desenvolvimento ${ }^{2}$, das mais diferentes matrizes teóricas. O enfoque adotado aqui é limitado a partir das variáveis apresentadas, ainda que se reconheça a existência de múltiplas dimensões, como o fazem, por exemplo, Sen $(2000)^{3}$ e Furtado (1984). Para Furtado, o desenvolvimento pode ser entendido como um processo de satisfação crescente das necessidades básicas da população e de redução das disparidades sociais (Furtado, 1984, p. 11). Segundo o autor, "desenvolver-se é ascender na escala de realização das potencialidades dos homens como indivíduos e como coletividade" (Furtado, 1984, p. 63).

O modelo de desenvolvimento significa o padrão de políticas públicas adotado e seu impacto previsto para a estrutura de produção de um país e, dessa forma, para o conjunto de sua sociedade. Sendo assim, por constituírem políticas públicas, os quatro tipos ideais são classificados como "Estados"; a adjetivação de cada um deles revela seu impacto esperado sobre a estrutura produtiva e, indiretamente, para a sociedade (autônomo, neo-utilitário; facilitador e desenvolvimentista), conforme será explicado mais adiante.

Esse impacto sobre a estrutura produtiva está associado à noção de mudança estrutural, que pode ser definida como o: "processo de longo prazo pelo qual os países experimentam a transformação e a diversificação de suas estruturas produtivas e tecnológicas e, como resultado, da composição de suas demandas intermediária e final" (Unido, 2013, p. 30, tradução nossa) ${ }^{4}$. Observa-se, assim, se as variáveis apresentadas, autonomia inserida e política de infraestrutura, contribuem para reproduzir ou alterar essas estruturas produtivas, principalmente a indústria e a economia de produtos primários (commodities).

O artigo está dividido da seguinte forma: a primeira seção apresenta os fundamentos teóricos e conceituais relacionados à transformação da estrutura produtiva e à promoção do desenvolvimento econômico. Detalha, ainda, as variáveis e como se relacionam: política de infraestrutura horizontal, vertical e a autonomia inserida. A segunda seção analisa as possibilidades de combinação dessas variáveis: Estado Neo-utilitário, Estado Autônomo, Estado Facilitador e Estado Desenvolvimentista. Realiza-se uma breve descrição de cada uma das categorias. Nas considerações finais, analisa-se a possibilidade de aplicação do modelo analítico.

(2) Ver, por exemplo, o conceito de Patrice Franko: “o processo de satisfazer as necessidades humanas básicas da população ao mesmo tempo em que aumentam as opções sobre como os recursos econômicos serão empregados hoje e no futuro para melhorar as escolhas que os cidadãos têm de fazer em seus cotidianos (Franko, 2003, p. 490, tradução e grifo nosso).

(3) Segundo Amartya Sen (2000), o crescimento econômico é uma condição necessária, mas não suficiente. O desenvolvimento passa pela expansão das liberdades, como a participação política e a oportunidade de receber saúde e educação.

(4) O conceito de mudança estrutural aqui adotado está associado à aquisição de capacidades produtivas e tecnológicas do paradigma tecno-produtivo vigente ou do próximo (Perez, 2002). Difere, por exemplo, da noção de Skocpol (1979), que entende a mudança estrutural como característica típica das revoluções sociais, nas quais se verifica a combinação das transformações política e social. 


\section{Infraestrutura, estado e desenvolvimento econômico: fundamentos teóricos}

A relação entre políticas públicas para infraestrutura e para a indústria não é algo novo na história. Carlota Perez demonstra que cada revolução tecnológica está associada a um conjunto de infraestruturas típico do paradigma tecno-produtivo. Por exemplo, a Era do Aço e das Ferrovias foi marcada pelas ferrovias que, combinadas com navios de aço e telégrafo, criaram redes transcontinentais de comércio e produção (Perez, 2002, p. 15). A Era da Informação combina a produção de microeletrônica com a infraestrutura de comunicação (internet). A associação entre novas tecnologias, indústrias e infraestrutura ocorre em cada uma das cinco revoluções tecnológicas categorizadas pela autora.

Justin Lin e Ha-Joon Chang (2009) realizaram um debate acerca do papel do Estado e da política industrial nos países em desenvolvimento, com implicações que dizem respeito à infraestrutura. Para Lin, devido à existência de falhas de mercado, como externalidades sobre a informação ${ }^{5}$ e problemas de coordenação, o Estado deve apoiar o surgimento de empresas e setores que façam uso das vantagens comparativas de um país, determinadas com base na dotação de fatores (trabalho, capital, recursos naturais). ${ }^{6}$ Por isso, defende um "Estado Facilitador", que apoie o setor privado a extrair o máximo de suas vantagens. Para ele, se adotada essa estratégia, a evolução das vantagens de um país, a passagem de um ramo de produção para outro mais avançado, ocorrerá naturalmente - como teria sido o caso da Coréia do Sul, que teria iniciado com indústrias intensivas em mão de obra, acumulado capital e então migrado naturalmente para setores mais dinâmicos.

Chang, por outro lado, entende que essa evolução passo a passo não se sustenta: é preciso desafiar as vantagens comparativas a fim de avançar em setores intensivos em capital e tecnologia. Para progredir, o país necessita ingressar em indústrias, ainda que sua dotação seja incompatível, como teria sido o caso da Coréia do Sul e da Finlândia. Segundo o autor, a acumulação de capital não é um processo abstrato, requer planejamento governamental e ações deliberadas de intervenção. A racionalidade dos agentes é limitada e existe incerteza nesse processo. Por isso, as empresas precisam ser subsidiadas e protegidas, como o foram em diversos países desenvolvidos que transformaram com sucesso sua estrutura produtiva - o que é demonstrado pelo autor em sua obra Chutando a Escada (Chang, 2002).

No mesmo sentido que Chang, Peres e Primi (2009, p. 3) entendem que a mudança estrutural é um processo com custos e barreiras que requerem a intervenção do Estado para serem superadas. De acordo com o contexto social e econômico de cada país, o Estado precisa financiar, produzir e articular a produção. O processo de desenvolvimento requer uma mudança

(5) Diz respeito à possibilidade de alguma empresa produzir inovação, arcando com seus custos, e ela ser utilizada por competidores e imitadores que não compartilharam o ônus (free rider).

(6) Refere-se ao papel que o Estado deve exercer para suprir carências em capital humano, físico e institucional, de modo a coordenar as mudanças e induzir melhorias. 
qualitativa da estrutura de produção. Baseado nas ideias de Kaldor ${ }^{7}$, o setor de manufaturas permitiria um conjunto maior de benefícios para a sociedade, visto que existiria uma tendência a um compartilhamento da renda agregada da indústria, além de um crescente número de trabalhadores empregados (Unido, 2013, p. 22).

De que forma ocorre essa transformação estrutural? Ricardo Hausmann (2011) explica que o processo de desenvolvimento está diretamente associado à diversificação da produção. Quanto mais desenvolvido é um país, não apenas ele é mais produtivo, mas produz diferentes tipos de bens. Além da questão da diversificação, o autor verificou, em seus estudos econométricos, que o grau de sofisticação das exportações de um país está correlacionado com seu nível de renda. Assim, em termos ideais, o melhor cenário combina diversificação e sofisticação de produtos. Todavia, para se chegar a essa situação, existem dois limitadores.

Primeiro, a criação de novos setores requer capacidades específicas: mão de obra especializada, sistema de logística e transportes, sistema de contratos e direito de propriedade, insumos específicos, que concorrem com outros usos alternativos (produtividade relativa), sistema regulatório e de proteção ao consumidor, entre outras (Hausmann, 2011, p. 528). No caso da infraestrutura, por exemplo, o transporte de minérios normalmente está associado a ferrovias, devido ao volume e peso da carga; o de soja envolve rodovias que acessem áreas rurais; o de petróleo, oleodutos; o de frutas; sistemas de armazenamento e refrigeração (Hausmann, 2011, p. 529). Da mesma forma, a produção em biotecnologia, semicondutores e nanotecnologia também exige capacidades específicas tais como as referidas.

Segundo, existe um problema semelhante ao dilema de causalidade entre ovo e galinha, sobre quem veio primeiro. O dilema reside no fato de que, para fabricar produtos mais sofisticados, novas capacidades específicas são necessárias. Porém, tais capacidades não são demandadas até que se inicie a produção nas novas atividades (Hausmann, 2011, p. 528). Em síntese, a nova produção requer capacidades específicas; mas essas capacidades só são demandadas assim que a produção se inicia. Nesse sentido e considerando que a dependência de trajetória importa, isto é, a estrutura produtiva, as instituições e o mercado já existentes limitam o leque de escolhas, a solução para esse dilema encontra um ponto de concordância entre Lin e Chang (2009). Se para Lin o Estado precisa explorar vantagens comparativas, para Chang é preciso desafiá-las. Ambos concordam, no entanto, que o desvio excessivo em relação à estrutura produtiva de um país é desaconselhável, pode ser utópico.

Em relação ao dilema do ovo e da galinha e a esse debate sobre facilitar ou desafiar vantagens comparativas, Hausmann entende que a mudança estrutural pode ocorrer a partir da utilização dos fatores e capacidades já existentes para outros propósitos. Para o autor, a transformação estrutural se trata menos de inventar novos produtos e mais de, por meio de um

(7) As três leis de crescimento de Kaldor são: $1^{\text {a }}$ ) há uma relação direta entre crescimento da indústria e a economia de um modo geral; $2^{\mathrm{a}}$ ) o crescimento da produtividade na indústria é um fenômeno endógeno; $3^{\mathrm{a}}$ ) a produtividade dos setores não industriais aumenta na proporção da produtividade da indústria. 
processo de "autodescoberta", encontrar setores em que o país pode atuar lucrativamente (Hausmann, 2011, p. 527).

Na elaboração de seu modelo analítico, o autor utiliza a metáfora da floresta. Uma árvore corresponde a um produto; um macaco, a uma firma. É mais fácil surgir novas atividades onde já existem macacos (firmas), visto que o país já possui capacidades requeridas iguais ou muito próximas. Produzir em árvores distantes exige capacidades não acumuladas, o que gera o dilema do ovo e da galinha e a respectiva dificuldade em criá-las. Assim, se na floresta do país há poucas árvores ocupadas e elas estão isoladas ou distantes uma das outras, é difícil gerar novas vantagens; em caso de crise, o país terá dificuldades em manter suas exportações. Contrariamente, se existe uma distribuição mais ou menos regular de árvores, com distâncias similares, o processo de progressão (catch up) isto é, saltar de uma árvore para outra, é facilitado. Essa teria sido a estratégia do Leste da Ásia: iniciou a produção em bens de menor agregado, tais como brinquedos e itens de vestuário, e gradualmente progrediu para automóveis, eletrônicos e informática (Hausmann, 2011, p. 530).

Além dessa relação lógica, também se realizou o mapeamento da floresta, isto é, a descrição de sua ocupação em termos de setores e de países. Hausmann descobriu que ela possui uma estrutura heterogênea, de centro-periferia. Os países mais ricos têm seus macacos nas áreas ricas da floresta; os pobres, nas regiões pobres. Em outras palavras, o nível de renda está diretamente associado à sofisticação das exportações. Em termos setoriais, também se identificou os produtos menos e mais conectados uns com os outros. De um modo geral, os dez mais conectados correspondem a manufaturas; os dez menos, a commodities ${ }^{8}$ - o que corrobora as ideias de Kaldor sobre a importância da indústria. Os países que possuem capacidades nessas árvores associadas à manufatura conseguem se expandir e diversificar sua produção (Hausmann, 2011, p. 531-32).

Decorre, desse conjunto de ideias, que políticas horizontais, tais como as do Consenso de Washington, são insuficientes. Tendo em vista que as capacidades produtivas são específicas de um produto ou setor, políticas minimalistas não bastam. Hausmann recorre à interessante metáfora dos sistemas do corpo humano. Por exemplo, o sistema circulatório é minimalista (low dimensional), isto é, possui um objetivo simples, transportar sangue. Já o sistema imunológico é complexo (multi dimensional), ou seja, precisa ser capaz de combater milhares de invasores e diferentes ameaças (Hausmann, 2011, p. 539). Em termos de políticas públicas, a solução minimalista corresponderia à estabilidade de preços; a complexa, à criação articulada de capacidades em várias dimensões (produtiva, tecnológica e infraestrutural). É preciso que, para saltar para novas árvores, o Estado aproveite a estrutura existente, mas aja a

(8) Entre os dez mais, encontram-se, por exemplo: partes de motor a combustão; materiais de borracha; artigos de metal; tubos, canos e conexões de ferro e metal; materiais de iluminação elétrica; tanques, reservatórios e contêineres. Entre os dez menos: seda bruta; bananas, sementes de cacau; tecido de juta; cortiça; óleo de rícino; platina e minério de estanho (Hausmann, 2011, p. 533). 
fim de gerar novas capacidades nos setores desejados. É o caso, por exemplo, de articular a infraestrutura com a indústria que o país deseja implementar.

A importância da produção industrial também pode ser observada a partir da visão de Erik Reinert (1996). Segundo o autor, economias baseadas em recursos naturais estão sujeitas à Maldição Tripla: 1) retornos decrescentes; 2) volatilidade de preços; 3) competição perfeita. Segundo o autor, o ideal de competição perfeita é justamente o que os países desenvolvidos e suas empresas buscam evitar na prática, visto que, nessa condição, não há lucros e os salários são pressionados para baixo. A volatilidade de preços, comum em commodities, diz respeito ao risco de flutuação que uma economia baseada na exportação de recursos naturais apresenta, pois o dinamismo de sua principal atividade estará sujeito aos oscilantes preços do mercado internacional. Já os retornos decrescentes correspondem à redução de benefícios de outros fatores quando um deles é mantido constante ${ }^{9}$. No caso da economia baseada em recursos, o caráter decrescente existe em razão da finitude dos recursos que, com o passar do tempo, não podem ser extraídos regularmente com a mesma quantidade ou qualidade:

Se especializada em agricultura, uma nação, cedo ou tarde terá de buscar terras menos produtivas; se a Noruega fosse especializada apenas no cultivo de cenouras, teríamos de plantar cenouras no topo das montanhas. Se especializada exclusivamente na pesca, a nação teria de pescar em oceanos vazios. Se especializada em mineração, a nação teria de extrair em reservas com qualidade cada vez menor (Reinert, 1996, p. 3, tradução nossa).

As três características da Maldição Tripla, conforme Reinert, reforçam-se mutuamente e mantêm ciclos de pobreza e de crescimento não sustentável. Essas duas últimas conformam a "dupla armadilha", isto é, o aumento de pobreza e degradação do meio-ambiente à medida que um país se especializa em vantagens comparativas no comércio internacional (Reinert, 1996, p. 3).

A situação de retornos decrescentes é frequente entre os países periféricos exportadores de matérias-primas. Na América do Sul, por exemplo, a crescente participação dos recursos naturais não foi acompanhada de um processo de progresso tecnológico (Cimoli; Ferraz; Primi, 2009, p. 37). Para Reinert, há duas opções, ambas inviáveis, para escapar da situação: a) ocupar novos territórios, com recursos disponíveis - inviável em razão da falta de territórios disponíveis no mundo contemporâneo; b) criar vantagens comparativas em atividades com progresso tecnológico e retornos crescentes (manufaturas) - inviável em razão do regime de livre-comércio estabelecido pelas instituições multilaterais. Essa última opção teria sido a estratégia conscientemente aplicada por Estados Unidos, Canadá e Austrália nos séculos XIX e XX, além de outros países centrais (Chang, 2002), o que tem levado a uma forte associação entre industrialização e desenvolvimento.

(9) Segundo Reinert, qualquer país ou empresa está sujeita a essa condição. O autor utiliza como exemplo hipotético a possibilidade de a empresa Microsoft crescer sua produção, mas não aumentar o espaço físico para os trabalhadores. Nesse caso, haveria retornos decrescentes, visto que um número crescente de empregados trabalharia aglomerado em um mesmo espaço reduzido (Reinert, 1996, p. 3). 
Quanto à inviabilidade de adotar vantagens competitivas no século XXI, fica mais por conta de exagero retórico do autor, visto que, apesar das restrições dos regimes internacionais de comércio (Reinert, 1996; Cunha; Perfeito; Pergher, 2014, p. 43; Rodrik, 2004, p. 33-34), existem espaços para criação de vantagens competitivas, inclusive a partir da infraestrutura. Para tanto,

[...] a intervenção estatal é necessária a fim de introduzir assimetrias e gerar incentivos que tornem possível explorar potenciais tecnológicos, criar e fortalecer atores do setor privado e apoiar a acumulação de capacidades e de conhecimento, baseada em uma avaliação das diferenças de produtividade entre os setores (Peres; Primi, 2009, p. 19, tradução nossa).

Dessa forma, a fuga dos retornos decrescentes e a migração para indústrias de maior valor agregado dependem da ação estatal, de suas capacidades e instituições (Chang, 2002; Hausmann, 2011; Evans, 2008). As capacidades tecnológicas estão associadas a retornos crescentes, efeitos de transborde, encadeamentos para trás e para frente, acumulação de capital e crescimento (Cimoli; Porcile, 2011, p. 548). A elevada difusão do paradigma das tecnologias de comunicação e informação, bem como a possível emergência de um novo paradigma, da bio, nanotecnologia e novos materiais, representa uma janela de oportunidades (Perez, 2002, p. 13; 20). Os recursos naturais da América do Sul poderão ter papel ativo na transformação e na concretização desse novo paradigma ou apenas continuarem a ser insumos de mercados inovadores mais avançados.

Como demonstra Carlota Perez, a cada ciclo completo de desenvolvimento, altera-se o rol de países que constituem o núcleo do sistema internacional ${ }^{10}$. Cada novo paradigma leva, ademais, a um descompasso entre as estruturas econômicas, sociais e políticas de um Estado, de modo que o arcabouço institucional passa a ser questionado e se inicia um período de transformação. As oportunidades serão aproveitadas, todavia, pelos países que forem capazes de construir capacidades tecnológicas, com capital humano e grandes empresas nessas novas áreas (Cimoli; Ferraz; Primi, 2009, p. 55) - tarefa que exige capacidade estatal e, sobretudo, institucional (chang, 2002). Estes são os motores fundamentais do desenvolvimento (Unido, 2013, p. XIX) $)^{11}$.

Naturalmente, esse processo de transição implica enfrentar desafios internos e externos. Os países desenvolvidos buscam e vão continuar buscando manter sua liderança nos setores de tecnologia mais avançada, impedindo a entrada de novos competidores (Unido,

(10) Observe-se que não se trata de uma regularidade rígida, tal como uma lei. A ideia aqui é demonstrar que os ciclos tanto promovem alterações nas posições de liderança entre os países já desenvolvidos, quanto promovem a inclusão e a exclusão de outros países nesse grupo.

(11) Nesse sentido, a Organização das Nações Unidas para o Desenvolvimento Industrial (Unido) apresenta o Ranking de Desempenho Industrial Competitivo (Competitive Industrial Performance - CIP Index), que congrega indicadores em três áreas: capacidade de produzir e exportar manufaturas; capacidades tecnológicas e competitividade internacional (nível de participação em relação a outros países). 
2013, p. xviii). A preocupação com a desindustrialização é uma questão que afeta tanto os países desenvolvidos quanto os em desenvolvimento, processo agravado pela Crise global de 2007-08, que levou a uma redistribuição mundial da produção de manufaturas ${ }^{12}$, com perda de empregos e redução do bem-estar nos países mais ricos (Unido, 2013, p. 16) ${ }^{13}$.

Desse modo, em um contexto internacional marcado pela transição de paradigma tecnológico e pela crescente competitividade na indústria, agravada pelas perdas nos países desenvolvidos, a capacidade do Estado em induzir mudanças e promover transformações é ainda mais decisiva. Para tanto,

Os países podem aprender a partir dos mercados internacionais e se tornar industrialmente mais competitivos se desenvolverem suas capacidades tecnológicas, expandirem suas capacidades produtivas e investirem em suas infraestruturas. Portanto, aumentar a competitividade industrial implica realizar intervenções seletivas mediante as quais vantagens comparativas são exploradas ao passo que novas vantagens competitivas são geradas (Unido, 2013, p. 7, tradução e grifos nossos).

Portanto, diante desse quadro sistêmico, à luz do debate apresentado entre aproveitamento versus desafio às vantagens comparativas, e considerando os impactos diferenciados entre economias baseadas em recursos e em manufaturas, bem como a importância das capacidades produtivas e tecnológicas para a mudança estrutural, as políticas de infraestrutura podem ser mecanismos de reprodução ou de transformação socioeconômica. A partir de uma operacionalização da classificação das políticas industriais (Peres; Primi, 2009, p. 12-13; Coutinho et al., 2012, p. 105, Cunha; Perfeito; Pergher, 2014, p. 41), construiu-se um modelo analítico em que as políticas de infraestrutura podem ser caracterizadas como horizontais e verticais ${ }^{14}$. Trata-se, naturalmente, de tipos ideais, que nem sempre enquadram perfeitamente a realidade, mas orientam a análise satisfatoriamente e auxiliam a tomada de decisão referente à implantação de políticas públicas.

A política de infraestrutura horizontal visa corrigir falhas de mercado. Também é estática, visto que não objetiva alterar a estrutura produtiva, toma as vantagens comparativas como dadas (Shapiro, 2013, p. 14), por isso é chamada de ricardiana. Os projetos

(12) Em 2010, China, Coreia do Sul e Taiwan representavam um quinto da produção global de manufaturas (Unido, 2013, p. 18).

(13) O relatório da Unctad (2014) indica dois movimentos que se aprofundaram após a crise de 2007-2008. O primeiro seria a tentativa de "reindustrialização" dos países desenvolvidos, a partir do reforço à estrutura industrial interna. Isso se dá mesmo em setores de baixo e médio valor agregado com a intenção de mitigar o desemprego elevado e diminuir a dependência externa. Já o segundo movimento dá-se no plano internacional a partir da interação entre estratégias nacionais que buscam o crescimento a partir da promoção de exportações (export-led growth). A Unctad (2014) sublinha que os resultados globais da dispersão dessa estratégia são inferiores aos que seriam auferidos se os países optassem por crescer com base no mercado interno e na distribuição de renda (wage-led growth). Todavia, há uma espécie de dilema do prisioneiro, já que em um mundo que tende ao wage-led growth, quem adotasse uma política export-led acumularia vantagens crescentes.

(14) Uma terceira possibilidade de classificação seria como "política de fronteira". Igualmente de viés schumpeteriano, na indústria corresponderia a setores como bio e nanotecnologia; na infraestrutura, o projeto de construção de um elevador espacial seria um exemplo. 
infraestruturais buscam reduzir tempo, distâncias, custos: seu foco primordial é busca pela eficiência. Por exemplo, um corredor bioceânico permitirá o trânsito de mercadorias e pessoas entre dois territórios, gerando uma ligação ótima entre dois extremos do continente.

A política de infraestrutura vertical é caracterizada pela busca da inovação, com a associação com outras políticas públicas, com vistas à alteração da estrutura produtiva. Os projetos infraestruturais não deixam de buscar eficiência, mas associada à geração de bemestar e à construção de capacidade produtiva e tecnológica. Por isso, os projetos verticais visam a encadeamentos para trás e para frente (Hirschman, 1961), ou seja, procuram vincular atividades fornecedoras e induzir novos processos e produtos. Por exemplo, é o caso do projeto do anel de fibra óptica sul-americano ${ }^{15}$, que não só aumentará a segurança do tráfego de informação na América do Sul, mas também permitirá novas indústrias e serviços associados a essa obra, conforme será examinado mais adiante.

De acordo com o nível de complexidade, as duas formas de política também podem ser diferenciadas. A política horizontal, basicamente, requer identificar gargalos logísticos, permitir que as cadeias produtivas fluam e que o mercado automaticamente se ajuste a essa melhoria de condições. Portanto, seu nível de complexidade é reduzido. Por outro lado, a política vertical exige a coordenação com outras políticas públicas, em especial a industrial. É preciso que o Estado leve em conta, em seu planejamento, sinergias potenciais entre infraestrutura, indústria e serviços. Por isso, seu nível de complexidade é mais elevado e requer maior capacidade estatal.

Os dois tipos de política de infraestrutura podem ser combinados com diferentes graus de entrelaçamento, ou inserção autônoma (embeddedness ${ }^{16}$, Evans, 2004), do Estado com a sociedade. Trata-se do grau de sinergia entre Estado e sociedade, combinando a autonomia das agências governamentais, de modo a evitar sua captura por interesses privados, com a parceria, ou seja, o suporte que as instituições públicas podem fornecer para apoiar o setor privado. A seguir, examina-se cada uma das variáveis e seus desdobramentos, que conduzem a um modelo analítico apresentado na sequência.

\subsection{Política de infraestrutura horizontal: eficiência}

A política de infraestrutura horizontal, em consonância com o sentido que lhe é atribuído na política industrial, não busca gerar transformação estrutural social e econômica. Não escolhe setores ou áreas prioritárias, visto que seu objetivo primordial é permitir a alocação

(15) Trata-se do projeto de construir um anel continental de redes de fibra óptica para integrar todas as redes nacionais da América do Sul em um único sistema de banda larga. Ao reduzir a distância do tráfego, diminuiriam os custos de comunicação e, dessa forma, seria possível ofertar internet de banda larga com custos menores.

(16) A expressão embeddedness, que não tem uma tradução consensual em Língua Portuguesa (incrustação, enraizamento), foi formulada por Polanyi (2000), e objetiva ressaltar que o mercado não é uma instituição pura, único determinante das trocas. Ele opera em meio a um conjunto de instituições econômicas e não econômicas, como a religião, os costumes e valores, e as instituições políticas. Por isso, uma análise econômica sem levar em conta esse contexto é falha. 
ótima de recursos, reduzindo tempo e custos. Trata-se de um conjunto de projetos que buscam, de um modo amplo, corrigir falhas de mercado e facilitar o fluxo de pessoas e mercadorias. Por essa razão, a questão da rentabilidade do investimento constitui variável importante nessa matriz, isto é, o quanto a infraestrutura representa em termos de redução de custos para uma empresa ou setor, ou a margem de retorno de uma obra para a empreiteira ou concessionária. Ainda que as políticas verticais também busquem a eficiência, no caso das horizontais essa busca é sua quintessência, seu princípio norteador.

Em relação à estrutura produtiva, a política horizontal pretende ser neutra. Todavia, é preciso ressaltar que a neutralidade acaba por privilegiar alguns setores (Rodrik, 2008, p. 6; Peres; Primi, 2009, p. 38). Por exemplo, é o caso da política cambial, que favorece a comercialização de determinados bens em detrimento de outros, de acordo com a taxa vigente, ou de uma política horizontal que fomente Pesquisa e Desenvolvimento e proteção da propriedade intelectual: beneficiará empresas com interesse em patentear inovações mais do que outras firmas não alcançadas por essa medida (Rodrik, 2008, p. 6). No caso da infraestrutura, uma nova hidrelétrica estenderá seus potenciais benefícios de acordo com a extensão de rede e a capacidade de sustentá-la. Uma empresa de alumínio, por exemplo, poderá extrair ganhos desproporcionalmente superiores da oferta abundante de energia do que produtores locais de artesanato. A construção de uma nova rodovia entre duas cidades poderá beneficiar mais empresas que realizem comércio intermunicipal do que os habitantes que não utilizam essa rota. Por isso, muitas vezes apenas após a política ser implementada, seu caráter parcial se revela (Peres; Primi, 2009, p. 44). Se a política opera em um contexto de desigualdade, ainda que ela pretenda ser isenta, poderá beneficiar desproporcionalmente os atores mais fortes (Coutinho et al., 2012, p. 104).

Ao facilitar a conexão de dois ou mais territórios, mediante rodovias, hidrovias, ou ferrovias, permite que as regiões explorem com mais intensidade suas vantagens comparativas. Por isso, ela é caracterizada como ricardiana. A intervenção estatal busca corrigir falhas de mercado, como problemas de coordenação e competição inadequada, bem como induzir externalidades (Coutinho et al., 2012, p. 103) - e, no modelo horizontal, com essas premissas, a política de infraestrutura é formulada e implementada.

Nos últimos anos, por exemplo, o caráter horizontal tem prevalecido na política industrial dos países sul-americanos ${ }^{17}$. Eles buscam aumentar a participação de suas empresas nos mercados internacionais, geralmente na área de recursos naturais (agrícolas ou minerais). Peres e Primi (2009, p. 53) procuram explicar esse perfil devido ao elevado custo e longo tempo de maturação que as políticas industriais possuem. Os projetos do Conselho Sul-Americano de

(17) Para o caso do Brasil, ver Cunha, Perfeito e Pergher (2014, p. 51, grifo nosso): “[...] verifica-se uma predominância de medidas horizontais tais como desoneração tributária, das exportações e da folha de pagamentos, novo marco da inovação e defesa e promoção comercial. Não obstante, há maior espaço para medidas verticais na política de financiamento do BNDES, nas compras governamentais e nos novos regimes setoriais". 
Infraestrutura e Planejamento (Cosiplan), sucessor da Iniciativa para a Integração da Infraestrutura Regional Sul-Americana (IIRSA), apresentam caráter predominantemente horizontal.

\subsection{Política de infraestrutura vertical: capacidades}

A política de infraestrutura vertical pressupõe a escolha de projetos a partir de uma visão estratégica. É transversal, pois interage com outras políticas, principalmente a industrial. Seu objetivo é construir capacidades, produtivas e tecnológicas. Embora possa gerar benefícios, não é intrinsecamente qualificada como positiva: a escolha de projetos e a construção das capacidades pode ser equivocada ${ }^{18}$.

Em sua Estratégia para infraestrutura para o período 2012-2015 (Infrastructure Strategy for FY12-15), o Banco Mundial apresenta uma visão coerente com os atributos da política vertical. Em especial, destaca a importância das sinergias e das complementaridades entre as políticas públicas. A infraestrutura deve identificar "pontos de alavancagem" que gerem efeitos de transborde na economia (Banco Mundial, 2012, p. 10). Em razão desse novo perfil da infraestrutura, o Relatório reconhece que, embora a participação do setor privado continue sendo importante, ela não é capaz de substituir o setor público, entendimento oposto daquele apresentado em outros documentos do Banco da década de 90 (Banco Mundial, 1994).

Mais importante, em virtude das transformações da economia global, os projetos infraestruturais verticais devem possuir um caráter "transformacional". Trata-se de iniciativas que produzam sinergias entre setores (transversalidade), visem à proteção do meio-ambiente (verdes), ao desenvolvimento social (inclusão) e à geração de benefícios territoriais (espaço) (Banco Mundial, 2012, p. 2). Por exemplo, um projeto de nova rodovia deve levar em conta seu impacto sobre o meio-ambiente, uma avaliação de riscos que pondere os riscos de possíveis desastres naturais, o uso de tecnologias da informação para monitoramento do tráfego e segurança dos usuários; os possíveis benefícios sociais às comunidades que estarão no trajeto, tal como o melhor acesso a hospitais e escolas. Em síntese, trata-se de buscar complementaridades entre a política de infraestrutura e as demais políticas públicas ${ }^{19}$.

(18) Por exemplo, durante a guerra do formato de videocassetes nos anos 1980, o modelo de gravação produzido pela empresa Sony, o Betamax, foi derrotado pelo VHS, da companhia JVC. Um país que tivesse acordado a instalação de uma planta produtora de Betamax em seu território e encadeado a indústria nacional a essa fábrica certamente teria prejuízos. No caso da infraestrutura, a seleção de um padrão tecnológico de comunicação obsoleto, ou de uma unidade de geração de energia elétrica que traga danos irreversíveis ao meio-ambiente, são exemplos de políticas verticais danosas.

(19) Além dessas dimensões, também pode ser incluída a questão da equidade de gênero. Na África do Sul, por exemplo, estima-se que o programa de eletrificação rural aumentou a participação das mulheres no mercado de trabalho em cerca de $10 \%$ em 5 anos, haja vista que diminuiu o tempo dedicado para tarefas domésticas (MCkinsey, 2013, p. 17). No Paquistão e na Guatemala, a infraestrutura de transporte permitiu o maior acesso à escola e à mobilidade das mulheres (Banco Mundial, 2012, p. 5). 
A política vertical parte do pressuposto de que o mercado, por si só, é incapaz de gerar transformação e garantir bem-estar social. O mercado não garante alocação de recursos com retornos crescentes (Peres; Primi, 2009, p. 18). Mais do que isso, em razão do próprio funcionamento do sistema econômico, que carece de mecanismos de ajuste automático (Peres; Primi, 2009, p. 20), o Estado precisa formular esse tipo de políticas. Se as instituições governamentais não detêm informação perfeita, o mercado da mesma forma não a possui (Rodrik, 2004, p. 40). Portanto, a infraestrutura vertical tem como objetivo, considerando as limitações do mercado, a alteração da estrutura produtiva. A ênfase é menos na quantidade e mais na qualidade da ligação infraestrutural e que tipo de capacidades são geradas junto a ela. Nessa perspectiva, a eficácia, entendida no sentido de atender aos objetivos estratégicos nacionais, sobrepõe-se à eficiência (Peres; Primi, 2009, p. 20).

Os investimentos em infraestrutura constituem desequilíbrios, assimetrias que transformam a produção, no sentido proposto por Hirschman (1961). Dessa forma, a política vertical visa à geração de encadeamentos para trás e para frente (backward e forward linkages). Em relação aos encadeamentos para frente, por exemplo, a construção de rodovias pode estar associada ao fomento de uma indústria regional de tecnologias da informação para controle de frotas, automação de procedimentos de alfândega, informatização do controle de frotas (Brasil, 2008, p. 81). Ferrovias podem gerar encadeamentos para trás, à medida que demandem a produção de aço, muitas vezes importado da China $^{20}$. Hidrovias podem ser articuladas com projetos de novas embarcações da indústria naval. Portos e aeroportos também demandam uma série de equipamentos de alta tecnologia para monitoramento de tráfego e de condições climáticas.

Se a política horizontal se caracteriza pelo perfil ricardiano, dado que a infraestrutura busca facilitar que as regiões explorem com mais intensidade suas vantagens comparativas, a política vertical é classificada como schumpeteriana. O caráter schumpeteriano reflete a dimensão de inovação da política vertical, no sentido de fortalecer setores industriais modernos e prioritários para um determinado país. Reconhece-se que, entre os autores de matriz neoschumpeteriana, há uma divergência acerca das políticas industriais, com autores que tendem a privilegiar medidas genéricas de incentivo à pesquisa e à inovação, por exemplo, enquanto outros defendem uma ação seletiva e discricionária da política industrial em relação

(20) No Brasil, a fabricação de trilhos pela Companhia Siderúrgica Nacional foi interrompida na década de 80 . O Programa de Investimentos em Logística, lançado em 2012 no governo de Dilma Rousseff, prevê a aplicação de R\$ 133 bilhões em nove trechos de rodovias e em doze trechos de ferrovias. Todavia, o Programa não foi acompanhado de um plano de preparação da indústria nacional para atender a demanda derivada dessas obras novas. A demanda é atendida pela importação de trilhos da China, fabricados a partir do minério de ferro importado do Brasil (Drummond, 2014). As siderúrgicas brasileiras alegam não haver escala suficiente para justificar a produção local, problema que seria eliminado se as políticas de infraestrutura regional, IIRSA e Cosiplan, fossem pensadas de modo articulado com a indústria. 
a setores específicos ${ }^{21}$. Não obstante, conforme se ressaltou, o caráter schumpeteriano aqui atribuído à política vertical objetiva retratar a formulação de políticas infraestruturais que fortalecem determinados setores e atividades, sobretudo os mais intensivos em tecnologia, como nano e biotecnologia, tecnologias de informação e comunicação (TICs), software e hardware e bens do complexo da saúde.

A respeito das inovações schumpeterianas, Mariana Mazzucato (2013) revela que existe um verdadeiro mito de que o setor privado é, em essência, dinâmico, criativo e inovador. O Estado tem assumido riscos e protagonizado a inovação em diversos setores da economia:

A maioria das inovações radicais, revolucionárias, que alimentaram o dinamismo do capitalismo - de estradas de ferro à internet, à nanotecnologia e a produtos farmacêuticos - estão associadas a investimentos 'empreendedores', capital intensivos, apoiados pelo Estado (Andrade, 2013).

Além da indústria farmacêutica, cuja pesquisa é financiada em grande parte com recursos públicos, um dos principais exemplos dessa relação é o aparelho Iphone, um dos ícones da sociedade informação e do capitalismo contemporâneo ${ }^{22}$. Portanto, é nítido o apoio do arcabouço institucional à inovação e à busca pelo aumento da competitividade das empresas nacionais.

Dada a complexidade da política vertical, o nível de capacidade institucional exigido para formular, implementar e avaliá-la é maior do que na horizontal (Peres; Primi, 2009, p. 17; Coutinho et al., 2012, p. 110). Enquanto a política horizontal basicamente identifica lacunas, "gargalos logísticos", muitas vezes a partir das demandas do setor privado, a política vertical requer não apenas identificar oportunidades de investimento e inovação, mas também garantir a sinergia entre diferentes políticas públicas a fim de fortalecer as capacidades inovativa e produtiva.

(21) Gadelha (2001, p. 152, grifo nosso) sintetiza a referida polarização existente na literatura neo-schumpeteriana: “É importante ainda notar que a polarização mencionada também aparece, ao menos de forma implícita, no interior do grupo dos autores neo-schumpeterianos. Enquanto, possivelmente, a maior parte dos autores - a começar por Nelson e Winter (1982), além de muitos outros como Metcalfe (1995), Mowery (1995) e Ostry e Nelson (1995) - são mais incisivos na refutação de uma ação do Estado mais seletiva e discricionária sobre a dinâmica econômica no nível dos setores ou tecnologias particulares, advogando uma ação mais genérica e horizontal, outros (Dosi et al., 1990; Soete, 1991; Freeman, 1995) posicionam-se de forma menos restritiva acerca da ação seletiva e estruturante do Estado, com ênfase nas situações de atraso econômico".

(22) Mazzucato (2013) demonstra que os principais componentes do Iphone foram financiados a partir de recursos estatais. A internet foi financiada pela DARPA (Defense Advanced Research Projects Agency), com apoio do Departamento de Defesa dos Estados Unidos (DoD), que queria estabelecer um novo sistema de comunicação militar no contexto da Guerra Fria. O sistema de navegação GPS (Global Positioning System) nasceu de outra iniciativa do DoD, o projeto NAVSTAR (NAVigation Satellite with Time And Ranging) igualmente a partir da necessidade militar de obter informações precisas sobre territórios no globo terrestre. O Sistema Siri, que permite a utilização de comandos por voz, bem como a própria comunicação por celular, foram financiados pela DARPA. A tela sensível ao toque (touchscreen) foi financiada a partir de duas concessões públicas, da CIA (Central Intelligence Agency) e da NSF (National Science Foundation). 
A seguir, pode-se observar um quadro sintético dos principais atributos das políticas vertical e horizontal:

Quadro 1

Políticas de infraestrutura vertical e horizontal: principais características

\begin{tabular}{|c|c|c|}
\hline Política de Infraestrutura & Horizontal & Vertical \\
\hline Fundamento teórico & Ricardiano & Schumpeteriano \\
\hline Caráter & Estática & Dinâmica \\
\hline Vantagens & Comparativas & Competitivas \\
\hline Exemplo IIRSA/Cosiplan & Corredor Bioceânico & Anel de fibra ótica \\
\hline Ênfase & Eficiência & Eficácia \\
\hline Mercado & $\begin{array}{c}\text { Autoajustável; } \\
\text { infraestrutura corrige falhas }\end{array}$ & $\begin{array}{c}\text { Insuficiente; infraestrutura } \\
\text { associada à indústria }\end{array}$ \\
\hline Estrutura Produtiva & Não altera (especialização) & Altera (inovação) \\
\hline Foco & Eficiência & $\begin{array}{c}\text { Capacidades produtiva e } \\
\text { tecnológica }\end{array}$ \\
\hline Política Pública & Setorial & Transversal \\
\hline Neutralidade & Neutra (em tese) & Seletiva \\
\hline Nível de Capacidade Institucional Requerido & Baixo & Alto \\
\hline
\end{tabular}

Fonte: Elaboração própria.

Entende-se que as políticas horizontal e vertical não são opções excludentes entre si. Sua implementação precisa levar em conta o território e a região que serão afetadas, bem como os objetivos setoriais. Como afirmam Cunha, Perfeito e Pergher (2014, p. 57), "não é suficiente haver políticas seletivas (a promoção de setores específicos) sem as horizontais". No caso da infraestrutura, políticas horizontais são aplicáveis em setores com encadeamentos já consolidados, que atendem aos objetivos do planejamento governamental, e necessitam apenas otimizar seus níveis de eficiência. No mesmo sentido, ambas as políticas são contingentes aos preços macroeconômicos, de modo que "podem não ser suficientes se retirarem incentivos para o incremento da produção, inovação e internacionalização" (Cunha; Perfeito; Pergher, 2014, p. 57). Não obstante, é preciso ressaltar que, em países em desenvolvimento com economias baseadas em recursos naturais, sujeitas à "tripla maldição" aludida por Reinert (1996), as políticas verticais possuem maior capacidade de alterar a estrutura produtiva do país e aumentar sua competitividade no sistema internacional.

\subsection{As relações Estado-Sociedade e a autonomia inserida}

Enquanto a caracterização da política de infraestrutura busca descrever essencialmente o grau de complexidade e de transformação estrutural, a Autonomia Inserida demonstra o nível de coordenação entre setor público e privado, cuja importância é reconhecida em diversos trabalhos (Wade, 2010; Ocampo, 2002; Rodrik, 2004). Segundo Ocampo, "é a única maneira de enfrentar as violentas forças centrífugas que caracterizam os negócios privados de hoje" (Ocampo, 2002, p. 328). 
O conceito é operacionalizado a partir da formulação de Peter Evans que, a partir das relações entre Estado e sociedade, explica o maior ou menor sucesso dos países em seus processos de desenvolvimento. Significa a combinação entre a coerência interna do Estado com sua capacidade de conexão externa, com a sociedade, a fim de promover a transformação industrial (Evans, 1993). Embora a autonomia inserida seja um atributo típico do Estado Desenvolvimentista, entende-se que constitui uma variável, com níveis oscilantes, de modo que pode ser utilizada para examinar outros casos que não o developmental state. Duas dimensões importam para examinar o relacionamento entre setor público e privado: autonomia e parceria ${ }^{23}$.

A Parceria diz respeito a "um grupo concreto de conexões que ligam o Estado íntima e agressivamente a grupos sociais particulares com os quais o Estado compartilha projetos conjuntos de transformação" (Evans, 2004, p. 93). Em outras palavras, trata-se do grau de sinergia entre a burocracia e os grupos privados no processo de transformação industrial.

A Autonomia refere-se ao grau de independência da burocracia em relação ao capital privado nacional. O excesso de autonomia pode representar um Estado predatório, avesso ao capital nacional, ou até mesmo um desinteresse pelo setor privado. A falta de autonomia pode ter como consequência a captura do Estado por grupos particulares e a existência de patrimonialismo.

As duas dimensões se completam: "Um aparato de Estado robusto e coerente facilita a organização de um capital industrial: uma classe organizada de industriais facilita um projeto conjunto de industrialização, que por sua vez legitima tanto o Estado quanto os empresários" (Evans, 2004, p. 291). Em relação ao papel de cada uma das dimensões, o autor afirma: "A parceria é necessária para obter informações e implementar políticas, mas sem a autonomia, a parceria vai se degenerar em um supercartel" (Evans, 1993; 2004, p. 91). Para Evans, "o segredo do Estado desenvolvimentista se encontra no amálgama destas duas dimensões" (Evans, 2004, p. 93).

Os Estados do Leste asiático são os exemplos tradicionais na combinação dessas duas dimensões. O MITI (Ministry of International Trade and Industry) japonês teria sido central na industrialização japonesa, visto que orientava o capital privado em direção a um processo de industrialização com crescente sofisticação tecnológica, mas guardava suficiente

(23) A variação de autonomia inserida pode ser observada a partir de diversos níveis de análise (entre países, no tempo, entre diferentes instituições, por exemplo) e depende também da estrutura social e do caráter interno do Estado. Sendo uma variável relacional por definição, apresenta níveis oscilantes. Na Coréia, por exemplo, o regime de Syngman Rhee praticamente abandonou o concurso público como mecanismo de recrutamento da burocracia, e passou a utilizar indicações pessoais, de modo que reduziu drasticamente a dimensão da autonomia. Esse regime aproxima-se mais do Estado Predatório do que do Desenvolvimentista (Evans, 1993), embora a Coréia seja considerada um caso clássico de sucesso. No Japão, apesar de que o MITI fosse "indubitavelmente a maior concentração de capacidade cerebral do Japão" (Evans, 1993), outros órgãos, como o Ministério da Agricultura, estavam sujeitos à maior incidência de práticas clientelistas e burocracias menos weberianas. Ademais, o próprio Evans previu o dinamismo e a transformação do Estado Desenvolvimentista de acordo com a evolução da industrialização e os objetivos da sociedade. No Japão e na Coreia, por exemplo, após o impulso inicial nas primeiras décadas, a burocracia passou a exercer um controle menos efetivo, de modo que cresceu a autonomia das elites industriais (Evans, 1993). 
distanciamento para não ser capturado pelos interesses particulares do empresariado local. A Coréia do Sul, marcada pela simbiose entre o Estado e os chaebols, e Taiwan e sua noção de "mercado governado" (Wade, 2010), também podem ser considerados casos exemplares ${ }^{24}$.

Os casos de sucesso no Leste Asiático constituem exceção, e não regra, e contaram com uma conjuntura favorável, em especial a destruição das classes agrárias durante a Segunda Guerra Mundial, e o apoio dos EUA no Pós-Guerra, que contribuiu para esse êxito (Wade, 2010). Nesse sentido, Evans reconhece que conectar o Estado e a sociedade é uma tarefa difícil, um "empreendimento ameaçador, mas essencial para os Estados intermediários" (Evans, 2004, p. 309). Ademais, reconhece-se que o Estado Desenvolvimentista do Leste Asiático era pouco inclusivo (Evans, 2008, p. 7), visto que a participação na tomada de decisão era quase que exclusiva da elite industrial. Hodiernamente, é preciso que a dimensão da inclusão seja fortalecida, de modo a não apenas distribuir os custos da transformação entre as forças sociais, mas também ampliar a legitimidade e a participação nas políticas públicas.

Seguindo a mesma lógica de argumentação, Dani Rodrik afirma que um arcabouço institucional capaz de equilibrar parceria e autonomia é mais importante do que a forma precisa que a política pública pode assumir (Rodrik, 2004, p. 5). Reconhecendo o papel da cooperação entre Estado e sociedade, o autor afirma:

Portanto, o desafio institucional crítico é encontrar uma posição intermediária entre plena autonomia e pela inserção completa. Excesso de autonomia para os burocratas resulta em um sistema que minimiza a corrupção, mas não fornece os incentivos de que o setor privado realmente necessita. Inserção demasiada para os burocratas, e eles acabam na cama com (e com os bolsos cheios) de interesses empresariais (Rodrik, 2004, p. 17, tradução nossa).

De fato, a dicotomia entre Estado e mercado perdeu espaço na era pós Consenso de Washington, ao passo de haver um relativo consenso de que "o desenvolvimento do moderno capitalismo depende de uma interação entre mercado e mecanismos fora dele" (Peres; Primi, 2009, p. 15).

Nesse contexto de enfraquecimento da dicotomia entre Estado e mercado, a variável autonomia inserida importa para qualificar o padrão de intervenção estatal. Quando apresenta níveis elevados, pode configurar o Estado Desenvolvimentista ou o Estado Facilitador. Em ambos, verificam-se autonomia e parceria presentes em níveis médios a altos. Em linhas gerais, há uma burocracia atuante e em conexão com grupos sociais privados que compartilham projetos de transformação com o Estado. Tal relação fértil, ao se combinar com o tipo de política infraestrutural, produz o padrão de Estado - Facilitador ou Desenvolvimentista. Se essa elevada cooperação contribui para políticas públicas que visam facilitar a habilidade do setor

(24) Ainda que o próprio Evans chegue surpreendentemente a categorizar a Coréia do Sul em determinado momento como caso intermediário (Evans, 2004, p. 38), e não como exemplo de Estado Desenvolvimentista. Acredita-se que isso se deva à ameaça à autonomia da burocracia em relação aos chaebols, por vezes considerada reduzida demais, ou seja, o maior predomínio do patrimonialismo (Evans, 1993). 
privado em explorar as vantagens comparativas de um determinado país, otimizar o aproveitamento da estrutura produtiva, então se configura o Estado Facilitador. Por outro lado, se a alta cooperação tende a alterar a referida estrutura produtiva, articular infraestrutura e indústria e criar capacidades produtivas e tecnológicas, caracteriza-se o Estado Desenvolvimentista.

No mesmo sentido, pode-se explorar o papel da autonomia inserida em relação aos outros dois tipos ideais. Quando apresenta níveis reduzidos, pode resultar em Estados Autônomo ou Neo-utilitário. O Estado Neo-utilitário se apresenta em um contexto de minimizar ou mesmo negar o papel da burocracia enquanto agente promotor do desenvolvimento, à medida que enfatiza o risco de captura do Estado por grupos de interesse e os prejuízos originados pela corrupção. Combina-se com o padrão de política de infraestrutura horizontal, isto é, há ausência de cooperação, ou até mesmo conflito, entre setor público e privado e pouca ou nenhuma iniciativa transformadora. Já o Estado Autônomo também apresenta baixa conexão entre a burocracia e os principais grupos privados nacionais. Entretanto, caracteriza-se por uma burocracia interventora e inovadora, que parte do pressuposto de que o mercado é insuficiente e é orientada estrategicamente.

Deste modo, o grau de Autonomia Inserida constitui variável decisiva para, combinada com o tipo de política infraestrutural, explicar a estratégia de desenvolvimento adotada pelos países. Desse modo, a combinação entre as variáveis e seus resultados esperados podem ser observados no modelo analítico apresentando a seguir.

\section{Infraestrutura e desenvolvimento: quatro tipos ideais}

A partir das variáveis expostas e de seus fundamentos teóricos, o modelo analítico proposto apresenta quatro tipos ideais. Sobre a construção da tipologia a partir de tipos ideias, é oportuna a visão de Fonseca (2014):

A forma bastante usual de construir conceitos nas ciências humanas é através da elaboração de tipos ideais, seguindo a tradição weberiana. Nesta, como é sabido, cada categoria é definida através de um conjunto de atributos ao qual se chega a partir de um exercício da razão, sem se esperar, na realidade fática, que se encontrem todos os atributos nas diferentes situações concretas ou casos. Os conceitos, então, são construtos mentais e a aproximação entre eles e o real é sempre probabilística (Fonseca, 2014, p. 3-4).

$\mathrm{Na}$ relação ente Estado e desenvolvimento, certamente existem outras variáveis relevantes além das variáveis apresentadas, como a posição do país no paradigma tecnológico, suas políticas macro e microeconômicas, o regime político, ente outras. A própria história de uma região importa, pois revela sua trajetória institucional, que restringe e delimita o leque de estratégias disponíveis para as políticas públicas (path dependence). Apesar da existência dessas outras dimensões, existe um trade-off na escolha metodológica: a adoção de um conceito muito extenso permite incluir mais casos, mas com menor força explicativa; por outro lado, um conceito muito restrito enquadra menos casos, mas com maior poder explicativo (Fonseca, 
2014 , p. 5). Nesse sentido, entende-se que a delimitação a partir das duas variáveis propostas - política de infraestrutura e autonomia inserida - explica satisfatoriamente os desdobramentos e resultados esperados a partir de suas possibilidades de combinação.

\section{1) Estado Neo-Utilitário}

O Estado Neo-Utilitário apresenta níveis reduzidos ou nulos nas duas dimensões. Em relação à infraestrutura, não há política pública ou ela é pouco significante, já que o mercado é responsável pela provisão infraestrutural. O grau de autonomia inserida é também muito reduzido, dado que não há que se falar em autonomia e parceria, pois o modelo nega a burocracia enquanto ator capaz de gerar benefícios. O modelo pode evoluir tanto para o Estado Facilitador (graficamente, à direita), se o grau de cooperação entre Estado e sociedade evoluir; ou para o Estado autônomo, na hipótese de adoção de projetos infraestruturais verticais conduzidos pelo Estado.

As premissas teóricas desse modelo residem na Teoria da Escolha Pública, que tem como expoentes Gordon Tullock, James Buchanan, entre outros, e constitui uma corrente da Teoria da Escolha Racional. Segundo essa visão, a ação governamental deve ser, sempre que possível, substituída pelo mercado. Isso porque o burocrata seria um agente autointeressado e racional, maximizador de utilidade, de modo que, se houver oportunidades de ganhos, não hesitará em utilizar a máquina pública em troca de vantagens pessoais. Agentes privados receberão privilégios de mercado e obterão, graças a esse acesso, benefícios superiores aos que, em condições normais, o mercado lhes forneceria (rent-seeking).

Com base nessa visão, o modelo enfatiza o risco de captura do Estado por grupos de interesse e os prejuízos originados pela corrupção. Entende-se, por essa ótica, que o Estado deve exercer o papel de um "vigia noturno", protetor dos indivíduos, dos contratos, e da propriedade (Evans, 1993; 2004, p. 54). Como destaca Evans, essa visão ignora o papel da história, dos costumes e das instituições. Nega o espírito público e a complexidade das interações sociais, bem como o papel do Estado na criação e no funcionamento dos mercados (Polanyi, 2000). Acredita que a "mão invisível" do mercado pode gerar bem-estar para o conjunto da sociedade (Evans, 1993; 2004, p. 54-55).

Um exemplo de Estado Neo-utilitário, à luz das variáveis desse trabalho, é o governo de Fernando Collor de Mello (1990-92) no Brasil. No que se refere à infraestrutura, apesar de ter criado uma pasta ministerial exclusiva para a área, não se vislumbram políticas públicas verticais relevantes, apenas a execução de uma agenda minimalista para o setor (políticas horizontais). Em relação à variável autonomia inserida, as dimensões de autonomia e parceria mostram-se nulas ou muito reduzidas. A respeito da autonomia, o governo de Collor tinha pouca crença no papel da burocracia enquanto portadora de visão de futuro, o que ficou notabilizado na sua famosa campanha de "caça aos marajás". Consequentemente, prevalecia a visão neo-utilitarista sobre a burocracia, considerada como excessiva, privilegiada e ineficiente. 


\section{2) Estado Autônomo}

O Estado Autônomo caracteriza-se pela combinação de políticas de infraestrutura de caráter vertical com baixo nível de inserção autônoma. A política infraestrutural é seletiva, orientada estrategicamente, e parte do pressuposto de que o mercado é insuficiente, por isso o Estado precisa intervir. Todavia, o nível de inserção autônoma é reduzido, visto que a dimensão "parceria" entre setor público é muito baixa ou até mesmo conflitiva. A autonomia da burocracia existe e prevalece na direção do modelo de desenvolvimento.

Se o nível de cooperação entre setor público e privado progredir, esse Estado se encaminha para o modelo de Estado Desenvolvimentista (graficamente, movimenta-se à direita). Porém, se os projetos infraestruturais forem abandonados, poderá migrar para o Estado neo-utilitário: conflito entre setor público e privado e ausência de iniciativas transformadoras (graficamente, movimento para baixo).

Um exemplo relativamente representativo do Estado autônomo é a Venezuela desde a chegada do governo de Hugo Chávez. Verificam-se iniciativas inovadoras na infraestrutura, de caráter vertical, com atuação seletiva em determinados setores e sentido estratégico. Todavia, o nível de autonomia inserida é reduzido, visto que a cooperação entre setor público e privado é muito baixa, e até mesmo conflitiva, de modo que a burocracia centraliza a gestão da economia. Essa falta de cooperação se reflete em prejuízos na capacidade produtiva e na implementação/execução problemática de projetos

\section{3) Estado Facilitador}

O Estado Facilitador combina um alto nível de autonomia inserida com projetos infraestruturais de corte horizontal, que buscam reforçar as vantagens comparativas do sistema produtivo nacional. Se o nível de cooperação entre setor público e privado retroceder, esse Estado se encaminha para o modelo de Estado Neo-utilitário: conflito entre Estado e sociedade e política de infraestrutura ausente ou pouco significativa (graficamente, movimenta-se à esquerda). Se passar a investir em políticas verticais, pode transformar a estrutura produtiva, incorporando tecnologia e aumentando o valor agregado de sua produção e, como resultado, se aproxima do Estado Desenvolvimentista (graficamente, movimento para cima).

O conceito do Estado Facilitador assemelha-se à visão do Banco Mundial apresentada em seu relatório de 1994, Infrastrucuture for Development. Influenciado pelo contexto da época, o relatório sugere três medidas: 1) aplicar princípios comerciais de operação na infraestrutura (autonomia gerencial e financeira, orçamentos baseados nas receitas dos usuários); 2) aumentar a competição, expandido a participação do setor privado ${ }^{25}$; 3 ) aumentar

(25) O Relatório sugere a adoção dos mecanismos BOT (build - operate - transfer), que são uma espécie de parceria público-privada mediante a qual o setor privado arca com os custos de construção da infraestrutura, mas, em contrapartida, recebe os direitos de explorar as receitas oriundas de sua utilização. 
a participação dos usuários, em diversas fases da política pública (planejamento do projeto, manutenção, monitoramento) (Banco Mundial, 1994, p. 8).

Entre as premissas do relatório, destaca-se o entendimento de que o bom desempenho da infraestrutura não está relacionado ao nível de renda do país, e sim a boas políticas setoriais. Para tanto, a variável chave estaria em os Estados serem capazes de prover ambientes institucionais favoráveis à operação das forças de mercado. Em termos teóricos, essa visão também está associada às premissas de North e Weingast (1989). Segundo esses autores, as instituições políticas precisam ser capazes de limitar a intervenção do Estado, de modo que os direitos privados e os mercados prevalecem: essas são as condições fundamentais do crescimento econômico (North; Weingast, 1989, p. 808). Com premissas semelhantes, Acemoglu e Robinson (2012) explicam o papel das instituições inclusivas que, ao garantir a propriedade privada e a concorrências, favorecem a inovação tecnológica e, por conseguinte, o crescimento sustentado. Haveria, por essa ótica, um ciclo virtuoso mediante o qual as instituições políticas e econômicas inclusivas se reforçam mutuamente, garantindo a pluralidade e a democracia e, ao mesmo tempo, diminuindo as chances de surgirem relações extrativas ou de um governante autoritário prejudicar o bom funcionamento desse capitalismo virtuoso com crescimento (Acemoglu; Robinson, 2012).

O conceito de Estado Facilitador foi formulado por Justin Lin e parte do pressuposto de que intervenção governamental se justifica tanto devido a falhas de mercado em termos da dificuldade de coordenar os agentes econômicos quanto em razão de externalidades em relação a assimetrias de informação sobre oportunidades de negócio mais ou menos lucrativas. Essas limitações condicionam a intervenção do governo a um papel facilitador, isto é, de favorecer o aproveitamento ótimo da estrutura produtiva já existente no país. O Estado facilitador consiste em "um Estado que facilita a habilidade do setor privado em explorar as vantagens comparativas de um determinado país" (traduzido de Lin; Chang, 2009, p. 484), com foco nos fatores que esse país possui no presente (recursos naturais, perfil da força de trabalho, capital, entre outros), não aqueles que gostaria de ter. Segundo o autor, se a intervenção governamental ocorrer em setores nos quais o país não possui vantagens, haverá prejuízo sobre a competição, já que haverá a necessidade de proteger firmas, gerando desperdício de esforços e atrasando a acumulação de capital (Lin; Chang, 2009, p. 484). Segundo Lin, adotar a estratégia de seguir vantagens comparativas permite a um país modernizar sua estrutura industrial e produtiva, como teria sido o caso das experiências históricas de desenvolvimento de Finlândia e Coréia do Sul. Na operacionalização do conceito de Lin, este trabalho assume que essa modernização preconizada pelo autor (catch up produtivo e tecnológico) não se verifica, embora adote os outros atributos e componentes do conceito de Estado Facilitador.

O Chile desde o advento da coalizão política da Concertación (1990-2010) constitui um exemplo de Estado Facilitador. Observa-se um alto nível de cooperação entre os setores público e privado, este último caracterizado por elevado grau de organização corporativa de setores e empresas chilenos, que se articulam, planejam e influenciam a tomada de decisão da burocracia nacional. Quanto à infraestrutura, predominam projetos de caráter horizontal, sem 
articulação com a política industrial ou busca pela inovação. O modelo tende a reforçar as vantagens comparativas existentes e favorece a exportação de commodities (cobre e outros minérios, frutas e peixes), com benefícios para o empresariado nacional.

\section{4) Estado Desenvolvimentista}

O Estado Desenvolvimentista apresenta elevados níveis de autonomia inserida combinados com políticas de infraestrutura verticais. Com base em relações sinérgicas entre os setores público e privado, os projetos infraestruturais buscam dinamizar a economia, promover setores e inovar, com foco no aumento da competitividade a economia. Por isso, estão associados normalmente com a política industrial e se destacam no planejamento governamental.

Em relação às possibilidades de transformação, o Estado Desenvolvimentista pode tornar-se Facilitador (graficamente, para baixo) à medida que perder seu caráter schumpeteriano, de inovação e apoio à indústria, e adotar medidas genéricas que favoreçam a economia sem diferenciação, reforçando vantagens comparativas existentes. Pode, também, tornar-se Estado autônomo se prejudicar as relações entre Estado e sociedade, de modo que o governo passe a gerir, sem parceria do setor privado, o desenvolvimento nacional.

O Estado Desenvolvimentista apresenta diversos elementos em comum com o Estado Desenvolvimentista conceituado por Evans (2004), mas também diferenças. Em comum estão: 1) a intervenção estatal em apoio à industrialização (papel ativo); 2) burocracia forte e meritocrática (weberiana); 3) autonomia inserida, que permite a institucionalização de canais de negociação entre setores público e privado (Fonseca, 2014, p. 11; Evans, 1993; 2004) ${ }^{26}$. Enquanto os itens 2 e 3 podem ser reunidos sob o mesmo prisma da autonomia inserida, adotase outro enfoque para examinar o maior ou menor grau de apoio estatal à industrialização. Enquanto Evans realiza um estudo comparado entre a cooperação ente setores público e privado, este trabalho articula essa variável com o papel da infraestrutura. Examina a relação das políticas infraestruturais com a estrutura produtiva, de modo a verificar se prevalece um padrão horizontal ou vertical. Dessa forma, conforme exposto, permite caracterizar o Estado e sua relação com o desenvolvimento.

Embora a ênfase na infraestrutura possa constituir uma novidade analítica, entende-se que não configura um novo tipo de Estado Desenvolvimentista, visto que se trata de um elemento pertencente ao conceito de desenvolvimentismo:

(26) Para uma excelente revisão da literatura e a aplicação do conceito de Estado Desenvolvimentista ver Herrlein Jr. (2011) e Cunha (2012). Herrlein Jr. defende a hipótese de que está em curso no Brasil o processo de construção de um Estado democrático para o desenvolvimento, que teria, entre seus diferenciais, as maiores participação e inclusão social, fundamentais para o desempenho produtivo do sistema capitalista nacional. Cunha (2012) demonstra que o chamado "Paradigma do Estado Desenvolvimentista" reúne não um único modelo, mas sim diversas experiências distintas e bem-sucedidas na industrialização, como Japão, Taiwan e Coreia do Sul, entre outros. Ademais, ressalta que diversos autores reconhecem a importância e prescrevem o Estado Desenvolvimentista, mas permanece o desafio analítico de como constituí-lo. A partir da questão da infraestrutura, conforme ressaltado, esse trabalho busca apontar um caminho possível. 
Entende-se por desenvolvimentismo a política econômica formulada e/ou executada, de forma deliberada, por governos (nacionais ou subnacionais) para, através do crescimento da produção e da produtividade, sob a liderança do setor industrial, transformar a sociedade com vistas a alcançar fins desejáveis, destacadamente a superação de seus problemas econômicos e sociais, dentro dos marcos institucionais do sistema capitalista (Fonseca, 2014, p. 28).

Portanto, embora a ênfase na infraestrutura não seja mencionada expressamente, constitui uma forma específica de intervenção estatal, de modo que, ao preservar os atributos do conceito desenvolvimentismo, não requer a formulação de um conceito radial (Fonseca, 2014, p. 33), como o fazem Bresser-Pereira e João Sicsú (novo-desenvolvimentismo). Da mesma forma, há diferentes enfoques, como os de Robert Wade, Ha-Joon Chang, Alice Amdsen, Peter Evans, entre outros, que possuem, não obstante, um núcleo comum de pressupostos passíveis de serem reunidos sob a matriz conceitual desenvolvimentista.

No Brasil, à luz do referencial analítico proposto, entende-se que o governo de Juscelino Kubitschek (1955-61) constitui um exemplo de Estado Desenvolvimentista. Em relação à variável autonomia inserida, verifica-se a parceria entre grupos ou agências da administração indireta e o setor privado, para quem eram concedidos benefícios à medida que as exigências estipuladas pelo governo eram cumpridas. Por exemplo, havia o uso de uma taxa de câmbio estável e subsidiada para importação de partes complementares do setor produtivo envolvido, a liquidação de empréstimos externos com taxas cambiais igualmente favorecidas, bem como o financiamento a longo prazo pelo BNDE para inversões.

Em relação à infraestrutura, a política aplicada caracteriza-se como vertical em virtude de pelo menos três razões. Primeiro, continha um sentido estratégico, com a integração territorial do Brasil a partir das rodovias radiais oriundas da recém construída Brasília, meta síntese do Plano de Metas. Segundo, estava articulada com a indústria, em especial a combinação entre expansão rodoviária e da indústria automobilística, de modo a promover encadeamentos para trás. Terceiro, visava ao incremento da capacidade produtiva e tecnológica. Portanto, o governo de JK pode ser caracterizado como Estado Desenvolvimentista.

\section{Considerações finais}

Este trabalho apresentou a proposta de um modelo analítico que pudesse categorizar as interações entre as diferentes políticas de infraestrutura e o padrão de relacionamento entre os setores público e privado. Em relação às primeiras, foram classificadas como horizontais, quando seu princípio norteador é a busca pela eficiência e têm como foco o fortalecimento de vantagens comparativas, e verticais, quando sua essência é a busca pela construção de capacidades produtivas e tecnológicas, articuladas à indústria, e seu foco é a criação de vantagens competitivas. A implementação de tais políticas depende do contexto social e institucional em que operam. Por isso, a inclusão da variável autonomia inserida permite avaliar o grau de sinergia entre os setores público e privado. 
Ao combinar as dimensões da política infraestrutural e da autonomia inserida, chegouse à tipologia que caracteriza o modelo de desenvolvimento. Desenvolvimento entendido de modo restrito às variáveis apresentadas, mas em um modelo que busca permitir a compreensão de quatro padrões claros e distintos entre si: o Estado neo-utilitário, o Estado autônomo, o Estado Facilitador, e o Estado desenvolvimentista. Tendo em vista sua fundamentação teórica, tais categorias podem ser aplicadas em estudos de casos em diferentes contextos e regiões do mundo. Uma vez identificada, a tipologia permite observar qual o resultado esperado das políticas públicas para o desenvolvimento de um determinado território.

\section{Referências bibliográficas}

ACEMOGLU, D.; ROBINSON, J. Why nations fail: the origins of power, prosperity and poverty. New York: Crown, 2012.

ANDRADE, C. Inovação, assunto à espera de uma retórica esclarecedora. Valor Econômico, São Paulo, 09 jul. 2013. Entrevista com Mariana Mazzucato. Disponível em: <http://www.valor.com.br/cultura/3192022/inovacao-assunto-espera-de-uma-retoricaesclarecedora>. Acesso em: 02 mar. 2014.

BANCO MUNDIAL. World Development Report 1994: infrastructure for development. Washington, D. C.: World Bank, 1994.

BANCO MUNDIAL. Infrastructure strategy for FY12-15. Washington D. C.: World Bank, 2012.

BRASIL. Ministério do Planejamento, Orçamento e Gestão. Estudo da dimensão territorial para o planejamento: estudos prospectivos - escolhas estratégicas. Brasília: MP, 2008. Disponível em: http://www.planejamento.gov.br/ secretarias/upload / Arquivos/spi/PPA/publicacoes antigas/plan territorial/estudo de plan ter/vol IV estudos prospectivos_escolhas_estrategicas.pdf. Acesso em: 10 dez. 2013.

CIMOLI, M.; FERRAZ, J.; PRIMI; A. Science, technology and innovation policies in global open economies: the case of Latin America and the Caribbean. Revista Globalización, Competitividad y Gobernabilidad, Washington D. C, v. 3, n. 1, Feb. 2009.

CIMOLI, M.; PORCILE, G. Learning, technological capabilities and structural dynamics. In: OCAMPO, J. A.; ROS, J. (Org.). The Oxford handbook of Latin American economics. Oxford: Oxford University Press, 2011.

CHANG, H. Kicking away the ladder: development strategy in historical perspective. London: Anthem Press, 2002.

COUTINHO, L.; FERRAZ, J.C.; NASSIF, A.; OLIVA, R. Industrial Policy and Economic Transformation. In: SANTISO, J.; DAYTON-JOHNSON, J. (Ed.). The Oxford Handbook of Latin American Political Economy. Oxford: Oxford University Press, 2012. 
CUNHA, A. et al. O Brasil diante da ascensão chinesa: os riscos da especialização regressiva. Austral: Revista Brasileira de Estratégia e Relações Internacionais, Porto Alegre, v. 1, n. 2, p. 135-175, jul./dez. 2012

CUNHA, A.; PERFEITO, P.; PERGHER, N. Estado e política de desenvolvimento no Brasil (2003-2014). In: HENKIN, H. (Org.). Política industrial e internacionalização. Porto Alegre: UFRGS/CEGOV, 2014. p. 36-70.

DRUMMOND, C. No jogo econômico, a China goleia o Brasil. Carta Capital, São Paulo, 13 jul. 2014. Economia. Disponível em: http://www.cartacapital.com.br/economia/no-jogoeconomico-a-china-goleia-o-brasil-9134.html. Acesso em: 29 set. 2014.

EVANS, P. O Estado como problema e solução. Lua Nova, São Paulo, n. 28-29, p. 107-157, 1993.

EVANS, P. Autonomia e parceria: estados e transformação industrial. Rio de Janeiro: Ed. da UFRJ, 2004.

FONSECA, P. C. D. Desenvolvimentismo: a construção do conceito. 2014. Disponível em: http://www.centrocelsofurtado.org.br/arquivos/image/201309121650480.Conceito\%20Desen volvimentismo\%20-\%20Pedro\%20Fonseca.pdf. Acesso em: 20 nov. 2014.

FRANKO, P. The Puzzle of Latin American Development. Lanham: Rowman \& Littlefield, 2003.

FURTADO, C. Cultura e desenvolvimento em época de Crise. Rio de Janeiro: Paz e Terra, 1984.

GADELHA, C. A. G. Política industrial: uma visão neo-schumpeteriana sistêmica e estrutural. Revista de Economia Política, São Paulo, v. 21, n. 4 (84), p. 149-171, out./dez. 2001.

HAUSMANN, R. Structural transformation and economic growth in Latin America. In: OCAMPO, J. A.; ROS, J. (Ed.). The Oxford handbook of Latin American economics. Oxford: Oxford University Press, 2011.

HERRLEIN JUNIOR, R. Estado democrático e desenvolvimento no Brasil contemporâneo: um ensaio de economia política. Porto Alegre: UFRGS/DECON, 2011. (Texto para Discussão, n. 1).

HIRSCHMAN, Albert O. Estratégia do desenvolvimento econômico. Rio de Janeiro: Fundo de Cultura, 1961.

LIN, J.; CHANG, H. Should industrial policy in developing countries conform to comparative advantages or defy it? A debate between Justin Lin and Ha Joon Chang. Development Policy Review, London, v. 27, n. 5, p. 483-502, 2009.

MAZZUCATO, M. The entrepreneurial state: debunking public vs private sector myths. Atenas: Anthem, 2013. 
Fernando Dall'Onder Sebben

MCKINSEY. Infrastructure productivity: how to save \$1 trillion a year. 2013. Disponível em: http://www.mckinsey.com/insights/engineering_construction/infrastructure_productivity.

Acesso em: 09 jan. 2015.

NORTH, D.; WEINGAST, B. Constitutions and Commitment: the evolution of institutions governing public choice in 17th Century England. Journal of Economic History, Cambridge, v. 49, n. 4, p. 803-832, Dec. 1989.

OCAMPO, J. A. Globalização e desenvolvimento. In: BANCO NACIONAL DE DESENVOLVIMENTO ECONÔMICO E SOCIAL. Desenvolvimento e globalização: perspectivas para as Nações. Rio de Janeiro: BNDES, 2002. p. 299-232.

PERES, W.; PRIMI, A. Theory and practice of industrial policy. evidence from the Latin American experience. Serie Desarrollo Productivo, Santiago, n. 137, fev. 2009.

PEREZ, C. Technological revolution and financial capital. The dynamics of bubbles and golden ages. Cheltenham: Edward Elgar, 2002.

POLANYI, K. A grande transformação. 2. ed. Rio de Janeiro: Elsevier, 2000.

REINERT, E. Diminishing returns and economic sustainability: the dilemma of resourcebased economies under a free trade regime. In: STEIN, H.; HESSELBERG, J.; HVEEM, H. (Ed.). International trade regulation, national development strategies and the environment: towards sustainable development? Oslo: Centre for Development and the Environment, 1996. p. 119-150.

RODRIK, D. industrial policy for the twenty-first century. Washington D. C., Nov. 2004. (CEPR Discussion Papers, n. 4767).

RODRIK, D. Industrial policy: don't ask why, ask how. Middle East Development Journal, Cairo, v. 1, n. 1, p. 1-29, 2008.

SEBBEN, F. D. O. Infraestrutura e desenvolvimento: estudo de caso sobre IIRSA e COSIPLAN. Tese (Doutorado em Estudos Estratégicos Internacionais)-UFRGS, Porto Alegre.

SHAPIRO, H. State intervention and industrialization: the origins of the Brazilian automotive industry. The Journal of Economic History, Cambridge, v. 49, n. 02, p. 448-450, Jun. 1989.

SEN, A. K. Desenvolvimento como liberdade. São Paulo: Companhia das Letras, 2000.

SKOCPOL, T. States and social revolutions. Cambridge: Cambridge University Press, 1979.

UNITED NATIONS CONFERENCE ON TRADE AND DEVELOPMENT - UNCTAD. Trade and Development Report 2014. Genebra: Unctad, 2014.

UNITED NATIONS INDUSTRIAL DEVELOPMENT ORGANIZATION - UNIDO. Competitive Industrial Performance Report 2012/2013. Viena, 2013.

VAN EVERA, S. Guía para estudiantes de Ciencia Política. Barcelona: Gedisa, 2002.

WADE, R. H. After the crisis: industrial policy and the developmental state in low-income countries. Global Policy, Durham, v. 1, n. 2, p. 150-161, 2010. 